\title{
On Evolution of Bank Runs
}

\author{
Jie-Shin Lin $^{1}$ \\ ${ }^{1}$ Department of Public Policy and Management, \\ I-Shou University, Taiwan \\ 1, Sec. 1, Hsueh-Cheng Rd., Ta-Hsu Hsiang, \\ Kaohsiung County, Taiwan \\ jslin@isu.edu.tw
}

\begin{abstract}
Bank runs are usually happened as such that depositors panic and following the consequence of interaction between depositors withdraw their deposits. It is an issue of debt obligation between bank and depositors and an issue of bank capitals distribution among depositors. We consider the role of information as the fears of bank failure to trigger a panic and construct a computational model to investigate the agents' learning and resulting evolution of bank runs.
\end{abstract}

Keywords: Bank Runs, Learning, Genetic Algorithms

\section{Introduction}

In recent years there has been a growing research interest in issues related to learning and adaptive behaviour. A number of studies have pursued a group of models of the economy which are often call "agent-based" models. A major influence in this computational work has been John Holland's work on genetic algorithms (GAs). A common feature of these models is the use of a population of heterogeneous, adaptive agents in contrast to the models with a representative agent; see for example, Axelrod (1990), Birchenhall (1995), Arifovic (2000), Chen (2002), and Lin (2005).

Since Diamond and Dybvig's work (1983), the phenomena of bank runs have been a growing research interest. ${ }^{1}$ When the bank runs happened, the direct impact to whom has to be suffered will be the bank and depositors. In a simple way, it is an issue of debt obligation between bank and depositors and an issue of bank capitals distribution among depositors. ${ }^{2}$ A bank run is that depositors panic and following the consequence of interaction between depositors withdraw their deposits. This could be the case that depositors perceive bank risk or the public think the bank is going to fail. Therefore, bank runs are believed to be contagious or propagation. In this study, we consider the role of information as the fears of bank failure to trigger a panic. We depart from standard

\footnotetext{
${ }^{1}$ See for example, Morris and Shin (1998) Cooper and Ross (2002) and Ennis (2003).

${ }^{2}$ There exists literature analyzing the uninsured demand deposit contracts leaving banks vulnerable to runs; see for example, Diamod and Dyvig (1983) and Jacklin et al.(1988).
}

formal theory which largely relies on the assumption of super rational, perfect foresight agents. Model our agents as adaptive and learning agents and dependant on incomplete information than as fully informed. Agents have heterogeneous view or perception on the bank risk which they use to individually decide their resource allocations. We construct a computational model and the genetic algorithm is used to update beliefs to investigate the agents' learning and resulting evolution of bank runs.

\section{The Model}

We use a special case of the economy in which there are $\mathrm{n}$ agents, each endowed with an amount $w_{i} \quad(\mathrm{i}=1 . . \mathrm{n})$ of the fund. The bank provides deposit contracts available to these agents. Agents may choose to simply store their endowment, or they may choose to invest a portion of their endowment in the bank in order to augment fund in the future. Since agents in the economy can save only by invest their funds in the bank. Denote individual agent's deposit as $D_{i}$. There will be no return for storage. In contrast, there is a return on investment i.e. $r_{D}$, the deposit interest rate.

The bank obtains fund from individual agents' deposits and pay interests to agents. The bank must keep a proportion of total deposits (TD), in store as liquid assets i.e. liquidity ratio, $\eta \cdot{ }^{3}$ It is assumed that the bank allocates all the rest of funds into the loan. Thus, the amount of loan is the difference between total deposit and liquid assets, i.e. $(1-\eta) \cdot$ TD. The return rate on the loan is $r_{L}$. However, there is a risk on the loan i.e. default risk. Denote the risk as $\gamma .{ }^{4}$ Therefore, in a case of liquid assets below a safety level, the last resolution the bank can do is to resolve the illiquid assets in order to procure the capitals, depending on the liquidating value which in turn is affected by the default risk. Hence, the maximum capitals the bank can obtain in facing the request of withdraw demand from depositors depend on the liquid assets and the liquidating value. In an extreme case, given the available amount of maximum capitals, if the bank still cannot satisfy the withdraw demand, the bank fails. To keep things simple, we will assume that there is no any intervention from the

\footnotetext{
${ }^{3}$ In general, the value of $\eta$ is around 0.3 .

${ }^{4}$ There exist many approaches to evaluate the risk of a bank theoretically and empirically, depending on the feature of study. We assume that the total asset of the bank comes from all agents' deposits and the loan is the main business resulting in bank risk.
} 
government authority to prevent any possible bank runs. Also, there is no role for deposit insurance to play.

For the agents i.e. depositors, their behaviour on resource allocations, storage or deposit in this model, will depend on information about the financial status of the bank. The only risk considered in this model is the default risk. The actual default risk is unknown to agents. Therefore, depositors perceiving information update their beliefs or perception about the risk. Each agent may have different belief regarding the unknown parameter $\gamma$. We focus on information-based runs. In our model, individual agents take into account which beliefs the other agents had possessed through population learning. There is an underlying process of contagion of opinion and behaviour spreading out through the learning.

Denote individual agent's perception or belief about the risk as $\gamma_{i}$. An individual agent $i$ 's utility is simply given by:

$$
U(S, D)=\ln S+\ln D
$$

where $S$ and $D$ denotes agent i's storage and deposit, respectively. The realized utility is determined by that whether the agent $i$ holds the deposit and therefore receives the interest, providing that the bank failure does not occur. However, there exists a possibility of bank failure and therefore agent $i$ will not receive the allocation which the deposit contract offers. This includes interest generated by the deposit and the deposit itself. To show how individual agents' belief or perception on the bank risk lead to the bank run, we specify agent $i$ 's deposit, $D_{i}$, depends on the belief. The belief is encoded in a bit string. The bit string is decoded to a parameter estimate and the result is a real number. ${ }^{5}$ A hyper-tangent function is used to transform the belief value into the agent's portion of deposit holding.

We depart from standard formal theory which largely relies on the assumption of super rational, perfect foresight agents. Our agents locally adapt, tethered to their current beliefs through learning. We model this process by a genetic algorithm. With this specification, the fact that beliefs are modelled and updated using a genetic algorithm is interesting in itself. The intention here, however, is to illustrate an alternative approach to genetic algorithm learning, and the GAs as a flexible tool in many different ways. Excellent introductions to GAs are available elsewhere and we assume the reader has some familiarity with the GA.

\section{Simulation}

The simulation results are intended to illustrate our agents' learning about bank risk to lead to the bank panic and bank run by implementation of genetic algorithm learning. It cannot be an exhaustive study of this

5 This follows a standard GA coding procedure. See Michalewicz (1996) for details. interpretation of genetic algorithm learning. The results reported below should give a general flavour of our findings and try to illustrate specific points. Each result we report is based on 100 simulations. The parameters, rates of crossover and mutation, for our GA are 0.8 and 0.03 , respectively. We consider the populations of two different size, $N=60$ and 120 . These parameter values all fall within the range recommended in the GA literature. ${ }^{6}$ Our simulations have the following structure.

(1) Randomly initialize the beliefs of the population of agents.

(2) Calculate withdraw amounts and check if the bank fails.

(3) Calculate individual fitness.

(4) Apply the GA operators to form a set of beliefs.

(5) Check stooping rules. If the stooping rules does not apply then return to 2 , otherwise stops.

We define the bank runs as such: all the amounts depositors have withdraw stand at least $5 \%$ of the total deposits of the bank. In addition, we can categorize these bank runs into different types, "Typical Bank Runs"; "Standard Bank Runs"; and "Abnormal Withdraw", according to the size and level which have happened. Typical Bank Run is classified as the size of withdraw arrive or over the liquid reserve rate of the bank. If the size of withdraw is between the liquid reserve rate and $15 \%$ of total deposits, it is classified as the Standard Bank Run. The size of withdraw never reaches the Standard Bank Runs is classified as the Abnormal Withdraw. Finally, "Normal" type is that all the amounts depositors have withdraw stand less than $5 \%$ of the total deposits of the bank.

\section{The Result}

Our main investigation is to see whether the bank runs emerge and eventually lead to bank failure. First our GA investigation showed that, in almost all of simulations, the bank does not fail. Also, we investigate three bank-run types i.e. "Typical Bank Runs"; "Standard Bank Runs"; and "Abnormal Withdraw" in different simulations. In some simulations, the bank does fail.

Fig. 1 presents the time series of the average withdraw rate (AWR) of the population i.e. "deposit flow away spread". The AWR starts from around $3.5 \%$ and the upward and downward fluctuations indicate that the average withdraw rate has a time varying nature as a result of the fact that agents have heterogeneous beliefs and continue to learn. Since agents continue to learn and

\footnotetext{
${ }^{6}$ See Grefenstette (1986) for details.
} 
therefore change their wealth allocations, storage and deposit. Consequently, wealth is redistributed across agents and therefore changes individual utility values and the average utility value of the population. Fig. 1 also shows the evolution of social wealth (SW) measured by the average utility value of the population. From the results, we can see the effects of information propagation or contagion leading to the emergence of "Abnormal Withdraw", "Standard Bank Runs", and "Typical Bank Runs" types chronically. However, after some periods of movement towards Typical Bank runs type, we can see that the AWR moves sharply downwards, eventually less than $5 \%$, and reach back to the "Normal" type. Hence, we see that right from the beginning the AWR increases and this continues to over $30 \%$. In the end, it is back to normal. In addition, our results show that the presence of bank runs is associated with lower social wealth than the "Normal" type. Since, the emergence of bank runs reduces the social wealth. Other simulations associated with different parameter sets have the similar results with some deviations. We do not report here.

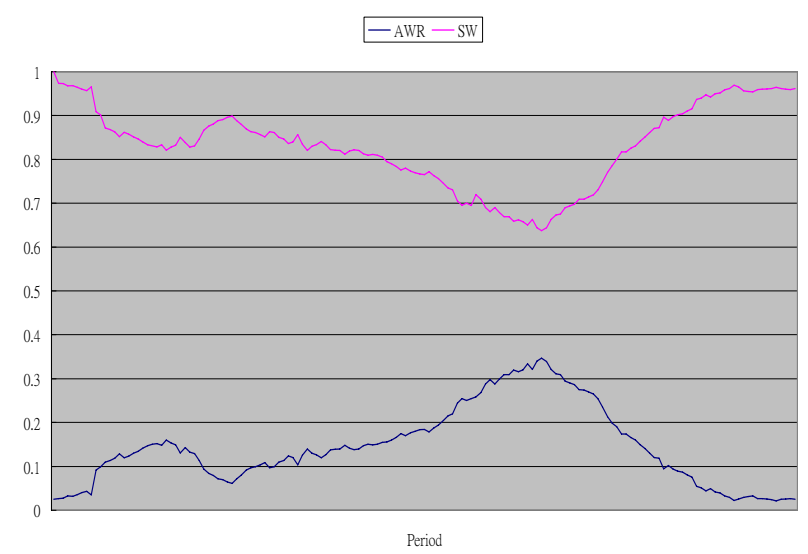

Fig. 1 AWR and Social Wealth

A special case in our simulation is the case of emergence of bank failure. Fig 2 presents the result. The AWR, initially, starts from a very high value, around 0.3 . The AWR stays around 0.3 for a while and dramatically increases to around 0.5 . As the population thinks the bank is going to fail, AWR increases to 0.6. Until the bank cannot satisfy the request of withdraw demand from the population and the bank will be forced to cease, i.e. bank failure. The AWR seemingly follows a stair-step walk. This observation has an implication of speculative overshooting, as the majority follows a panic belief. ${ }^{7}$. These beliefs depend mainly, among other things, on the behaviour and beliefs of others, in which there is a process of mutual imitative contagion among agents, which is the effect of information contagion. Of relevance is Kirman's (1993) formalisation of recruitment in ant populations. The recruitment process

\footnotetext{
7 The importance of psychological factors and irrational factors is highlighted in many models of financial markets (Shiller, 2000).
}

"systematically gives rise to the asymmetric exploitation of symmetric sources" (Kirman, 1993). The recruitment process in the context of the model is the contagion process where individual agents try to perceive information about the bank risk through population learning and there is a "general externality". 8

\section{Conclusion}

Our simulations show that the economy starts from a "Normal" state. There emerge different bank runs types and afterwards gradually eliminated. ${ }^{9}$ The process of development is dynamic. It stays in one type for a considerable period before switching to another. Types are continually created as the result of learning in which agents learn and other agents are learning as well, in respond to the learning. The population behaviour in the context of the model is the propagation or contagion process in which individual agents try to perceive the information. The case of bank failure is only investigated in experiments starting from a high AWR.

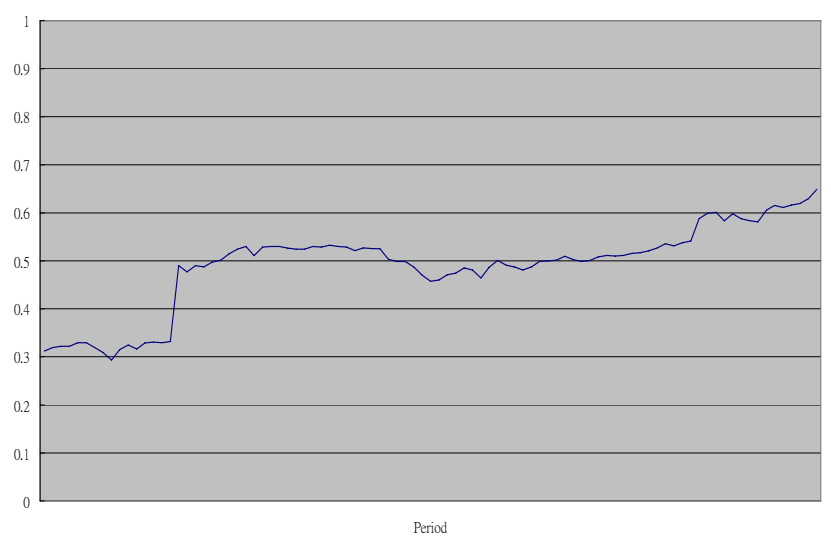

Fig. 2 AWR - STANDARD

\section{References}

[1] Arifovic, J. (2000). "Evolutionary Algorithms in Macroeconomic Models." Macroeconomic Dynamics 4: 373-414.

[2] Axelrod, R. (1990), The Evolution of Cooperation, Penguin.

[3] Birchenhall, C. R. (1995). "Modular technical change and genetic algorithms." Computational

\footnotetext{
8 In other words, an agent possess a belief may lead, through externality, to the other agent concurring in that belief.

${ }^{9}$ We do not argue that there is no need for government and institutions in place to prevent bank runs. The reason of bank runs is complex and we do not spell out here. There exist literature about the determinants of bank runs, for example, economic fundamentals and sunspots phenomena.
} 
Economics 8: 233-253.

[4] Chen, S-H (2002). Genetic Algorithms and Genetic Programming in Computational Finance. Boston, Kluwer Academic Publishers.

[5] Cooper, R. \& T. W. Ross (2002), "Bank runs: Deposit Insurance and Capital Requirements", International Economic Review, 43, No 1, 55-72.

[6] Daimond, D. \& P. Dybvig (1983), "Bank Runs, Deposit Insurance and Liquidity", Journal of Political Economy, 91, 401-19.

[7] Ennis, H. M. (2003), "Economic Fundamentals and Bank Runs", Federal Reserve Bank of Richmond Economic Quartely, 89/2, 55-71.

[8] Grefenstette, J. J. (1986), "Optimization of control parameters for genetic algorithms.", IEEE Transactions on Systems, Man, and Cybernetics 16(1):122-28.

[9] Jacklin, C\&S. Bhattacharya (1988), "Distinguishing Panics and Information-based bank runs: Welfare and Policy Implications", Journal of Political Economy, 96, 568-92.

[10] Kirman, A. (1993). "Ants, rationality, and recruitment." Quarterly Journal of Economics 108(February): 137-156.

[11] Lin, J.S. (2005),"Learning in a Network Economy", Computational Economics, 25, No.1-2, 59-74.

[12] Michalewicz, Z. (1996) Genetic Algorithms + Data Structures $=$ Evolution Programs, Springer.

[13] Morris, S. \& H. S. Shin (1998), "Unique Equilibrium in a Model of Self-Fulfilling Currency Attacks", American Economic Review, 88, 587-97.

[14] Shiller, R. J. (2000). Irrational Exuberance. NW, USA, Princeton University Press. 